\title{
POLYTENE CHROMOSOMES OF DIFFERENT SUBFAMILIES OF FAMILY CHIRONOMIDAE, DIPTERA.
}

\author{
By P. Michailova \\ Institute of Zoology, Bulgarian Academy of Sciences, \\ 1, Tzar Osvoboditel boul., 1000 Sofia
}

The Chironomidae has still not been fully studied from the systematic aspect. The conventional morphometric method does not always provide an opportunity for determining separate forms which should, on the basis of a number of biological characteristics be considered "well differentiated species". The morphometric method can "work" for some species of chironomids only at one stage of ontogenesis, while for others it may not "work" at all. There are no clearly distinct differences in the larval stage of many related species and many of them are thus known merely as groups of species or larval forms. The polytene chromosomes appeared to be particularly promising for taxonomic diagnosis of chironomid species combined with the morphological characteristics of the separate developmental stages.
The diagnostic value of karyotype characteristics like the number and morphology of the polytene chromosomes, marker zones, number and localization of "weak points", Balbiani rings and nucleoli is great. The giant size and constant specific band structure of polytene chromosomes allows for its wide application as a stable diagnostic character in the systematics of the Chironomidae. Every band represents a complex of identical chromomeres adjacent to each other of solid spiralized DNP regions (BEERMANN 1952). The reasons of the pairing of homologues in polytene chromosomes is not known yet. It may be that the physical joining between sister chromosomes in homologous sections plays an important role. The protein interaction between sister chromomeres can not be excluded either (ANANIEV, BARSKY 
1985). In most species of Chironomidae the homologues are paired, with some exception in genera: Chironomus (KE Y L 1962) and Glyptotendipes (MICHAILOVA 1989a). An asynapsis in the polytene chromosomes reveals differences in the chromomere and chromonema organization of the homologues and their cyclic state (PROKOFIEVABELgOvSKAJA 1986). The asynapsis in polytene chromosomes can also be favoured by heterozygous inversions or gene differences in homologues. These peculiarities are easily seen in inter-species hybrids. Each chromosome in the karyotype of every species has its unique band pattern. Sometimes under the influence of various factors (e.g. infection, salinity, different environments) the banding pattern changes: becoming diffused or super contracted or shortened. The shortening of the chromosomes is caused by the fusion of groups of neighbouring bands into chromatin blocks. In these cases the inactivation of transcription processes leads to DNA condensation in earlier active regions accompanied by association of separate bands, resulting in shortened chromosomes. However, there is no alteration to the basic banding markers of the chromosome.

Sequences of band pattern can be changed through different chromosome rearrangements: inversions, translocations (homozygous reciprocal translocations and fusions). In most cases heterozygous inversions ensure plasticity of the species. When the aberration has a high selective value, it is further stabilized by selective forces and spread in the population, so becoming a constant characteristic of the species. Such chromosome differences are directly linked to isolating mechanisms (disturbances occurring in the meiosis of hybrids, unbalanced gametes formed). Among species of the successful genus Chironomus a great similarity of chromosome band patterns has beed found. The genetic material has been redistributed through different chromosome aberrations. On the basis of homozygous reciprocal translocations species of this genus may have the chromosome arm combination: $\mathrm{AB}, \mathrm{CD}, \mathrm{EF}, \mathrm{G}$ or AE, BF, CD, G etc.. Species having the same chromosome arm combination may be united into complexes (KEYL 1962). So, the karyotype based on polytene chromosomes plays an integrating role in the systematics of the Chironomidae. In these complexes species are differentiated on the basis of homozygous inversions (KEYL 1962). Homozygous inversions are responsible for divergence of sibling species and in the microevolution differentiation of the species
(Michailova 1989, a,b), (KIKNADZE et al. 1991). In the most primitive subfamilies (Diamesinae, Orthocladiinae) different types of rearrangements have been incorporated during the karyotype evolution, so that only a few sections of the polytene chromosomes of related species have common band patterns or distinguishable by homozygous inversions (MichaILOVA 1989 a).

The special appearance of some polytene chromosome sections, the so called "weak points" can be used as a species characteristic. There are constructions of chromosomes which are underreplicated during polytenization. Also, there are differences in the band structure organisation of chromosomes of related species. These can be revealed by "C" and "Q" banding methods. Common banding patterns have been found in arms of different species belonging to other genera. These common banding patterns are considered as "basic" or "plesiomorphic", existing in a hypothetical stem species before separation (WÜLKER 1980). Such basic patterns have been established in genera Glyptotendipes, Chironomus, Endochironomus, Micropsectra, Brillia, Orthocladius, Cricotopus, Prodiamesa (Michailova 1989 a).

The number and position of Balbiani rings and nucleoli are a significant taxonomic character for the family. Within the larval salivary glands of chironomids a functional differentiation of distinct glandular regions has been established in some species (Acricotopus lucidus, Axarus sp.). This is reflected in the level of the polyteny of the chromosomes and in the expression of cell specific Balbiani rings. More primitive subfamilies (Orthocladiinae, Diamesinae) have great functional activity, realized by Balbiani rings. They can be localized in one and the same chromosome (Diamesinae) or distributed in different chromosomes (Orthocladiinae). In these subfamilies the position of nucleolus is not fixed. In the subfamily Chironominae very often (with few exceptions only) the nucleolus and a Balbiani ring are situated in the short chromosome.

An important taxonomic character is the manifestation of the centromere region in polytene chromosomes. In most species of the genera Chironomus, Endochironomus, Micropsectra, Dicrotendipes, Acricotopus the centromere region is represented by a dark band. In species of genera Cricotopus, Orthocladius, Glyptotendipes the centromere region is a large dark block. The chromosomes of some species of the genera Cricotopus, 
Parachironomus, Orthocladius (MichaILOva 1989 a) and Lipinella (KERKIS et al. 1985) have been combined in a chromocentre. It has been formed as a result of a number of ectopic contacts arising between the separate replicates in the precentromere regions of the chromosomes. The inference to be drawn is that the evolution of chromosomes of these groups has proceeded much more rapidly than the evolution of external morphological characters. This phenomenon of a high karyotypic diversity among closely related species manifests the so called "chromosome tachytely" evolution (MARKS 1983).

\section{References}

ANANIEV, E. V. \& BARSKY, V. E. (1985). Electrone microscope map of Drosophila polytene chromosomes: 1-95.

BeERmann, V. (1952). Chromosomenkonstanz und spezifische Modifikation der Chromosomenstruktur in der Entwicklung und Organdifferenzierung von Chironomus tentans. - Chromosoma, 52: 139-198.

Kerkis, I. E., KiKnadze, I. I. \& Shilova, A. I. (1985). Karyological characteristics of Lipinella arenicola SHILOVA (Diptera, Chironomidae). -Tsitologia, 27: 1410-1413.
KEYL, H. (1962). Chromosomenevolution bei Chironomus. II. Chromosomenumbauten und phyogenetische Beziehungen der Arten. -Chromosoma, 13: 496-541.

Kiknadze, I., Shilova, A., Kerkis, I., Shobanov, N., ZE L E n Z O V, N., GrebenJuK, L., Is t O Min A, A., Preslov, B., (1991). Karyotype and morphology of larvae of Chironomini. N. Novosibirsk, $115 \mathrm{p}$.

MARKS, I. (1983). Rates of Karyotype evolution. Syst. Zool. 32, 2: 207-209.

M ICHAILOVA， P. (1989 a). The polytene chromosomes and their singnificance to the systematics of the family Chironomidae, Diptera. -Acta Zool. Fennica, 186: 1-107.

Michailova, P. (1989 b). Cytotaxonomic studies on the experimental hybrid of Glyptotendipes barbipes (STAEGER) and Glyptotendipes salinus MICHAILOVA (Diptera, Chironomidae). -Biol. Debr. Oecol. Hung., 32, 2: 141-150.

Prokofieva-Belgovskaja, A. A. (1986). Heterochromatin regions of chromosomes. $431 \mathrm{p}$.

WÜLKER, W. (1980). Basic patterns in chromosome evolution in the genus Chironomus (Diptera). -Z-zool. Syst. Evolutionforsch., 18,2: 112-123. 